\title{
The acute inflammatory response to myocardial infarction: imaging with indium-111 labelled autologous neutrophils
}

\author{
D BELL, * M JACKSON,* A M MILLAR, $\ddagger$ J J NICOLL, $†$ M CONNELL, $\dagger$ \\ A L MUIR* \\ From the ${ }^{\star}$ Departments of Medicine, $\nmid$ Medical Physics, and $\ddagger$ Radiopharmacy, Royal Infirmary, Edinburgh
}

SUMMARY The uptake of indium-111 labelled neutrophils was examined in 30 patients with acute myocardial infarction by planar imaging and single photon emission computed tomography. The time from venepuncture to reinjection of the autologous labelled neutrophils was $<2.5$ hours and imaging was carried out 24 hours later. Twenty three patients had a positive uptake of neutrophils in the myocardium and imaging was improved by single photon emission computed tomography. There was a significant difference between the intervals from the onset of chest pain to injection of labelled neutrophils between patients with positive and negative images; early reinjection was more likely to produce a positive image. Indeed, all nine patients reinjected within 18 hours of the onset of symptoms had positive images.

The results suggest that the stimulus for activation and migration of neutrophils is transient; this is an important factor if neutrophil release products play a role in cell damage after coronary occlusion.

After myocardial infarction, myocardial cell death and damage produce an acute inflammatory response characterised by the migration of neutrophils into the area of infarcted muscle. Histological examination shows neutrophil infiltration into the infarcted area within 24 hours and the response is maximal at 4-5 days. ${ }^{12}$ As part of the inflammatory response, neutrophils release oxygen derived free radicals and proteolytic enzymes that in certain circumstances may increase tissue injury. To date, the neutrophil has been implicated in damage to pulmonary capillaries in adult respiratory distress syndrome and may also contribute to the pathogenesis of emphysema. No definite role has been established for the neutrophil extending myocardial damage in man, but in animal models of myocardial infarction, infarct size can be limited by neutrophil inhibition. ${ }^{34}$

Although experimental studies have shown uptake of indium-111 ( $\left.{ }^{111} \mathrm{In}\right)$ labelled neutrophils in infarcted myocardium ${ }^{56}$ studies in man have produced conflicting results. McDougall et al did not

Requests for reprints to Dr D Bell, Department of Medicine, Royal Infirmary, Edinburgh EH3 9YW.

Accepted for publication 30 September 1986 detect uptake of labelled cells in three patients with acute infarction. ${ }^{7}$ The time of injection of labelled cells may be of importance, however, because Davies and colleagues obtained positive images when the time to reinjection was short. ${ }^{8}$ They also found that positive images were more likely in younger patients.

We have used ${ }^{111}$ In labelled autologous neutrophils in 24 patients with acute myocardial infarction. Our results confirm the importance of early injection of the neutrophils in obtaining a positive image. We also found that reconstructional imaging from single emission photon computed tomography can be used to resolve difficulties in the interpretation of planar imaging.

\section{Patients and methods}

\section{PATIENTS}

We studied 30 patients with a diagnosis of acute myocardial infarction based on a history of prolonged ischaemic chest pain ( $>30$ minutes), electrocardiographic changes associated with myocardial infarction, and a rise in serum creatine kinase to at least twice the upper limit of normal. All gave informed consent, and the study had the approval of 
our institute's ethical committee. Table 1 shows patient details and a full record of the drugs administered within the first 24 hours of myocardial infarction.

\section{PREPARATION OF ${ }^{111}$ IN LABELLED} NEUTROPHILS

Autologous neutrophils were separated from whole venous blood and labelled with ${ }^{111} \mathrm{In}$-oxine. ${ }^{9} \mathrm{We}$ used an aseptic technique to withdraw whole blood $(60 \mathrm{ml})$ into a syringe containing 300 units of preservative free heparin. Duplicate samples $(25 \mathrm{ml})$ of blood were layered over $12 \mathrm{ml}$ of mono-poly resolving medium (Flow laboratories) in a sterile tube and centrifuged at $400 \mathrm{~g}$ for 60 minutes. This produced a top plasma layer, two distinct cell bands, and a red cell pellet. We collected $8 \mathrm{ml}$ from the top plasma layer and centrifuged it at $1000 \mathrm{~g}$ for 10 minutes to obtain platelet poor plasma. The remaining plasma and upper cell band were discarded and the neutrophils were recovered from the lower cell band. The neutrophils were washed by diluting the recovered cell suspension to $40 \mathrm{ml}$ with phosphate buffered saline $\mathrm{pH} 7 \cdot 4$, centrifuging at $400 \mathrm{~g}$ for 10 minutes, and discarding the supernatant. The cell pellet was resuspended in $10 \mathrm{ml}$ phosphate buffered saline and $1 \mathrm{ml}$ of ${ }^{111} \mathrm{In}$-oxine solution (20-40 MBq) was added drop by drop to the suspension of neutrophils. After incubation at room temperature for 15 minutes, $3 \mathrm{ml}$ platelet poor plasma was added and the cell suspension was centrifuged at $250 \mathrm{~g}$ for 10 minutes. The supernatant was discarded, the neutrophil cell pellet was resuspended to a total volume of $5 \mathrm{ml}$ with equal parts of phosphate buffered saline and platelet poor plasma and the labelled cells were then ready for reinjection.
PATIENT IMAGING

All patients were injected at a fresh site with ${ }^{111} \mathrm{In}^{\mathrm{C}}$ labelled autologous neutrophils within two and $\overrightarrow{\vec{s}}$ half hours of the initial venesection. Preliminaryo studies had suggested that the optimal time for imaging was 24 hours after the injection of labelledes. neutrophils and we used this imaging time in all our patients. Thus the earliest imaging time for anyo patient was 36 hours after the onset of chest pain and ${ }^{\text {cs }}$ the latest was 57 hours. Each patient was imaged $\overrightarrow{0}$ while supine and planar images were acquired in the $-\overrightarrow{-}$ anterior, left anterior oblique, and left lateral posi- $-\omega$ tion for 100000 counts with a gamma camera (GE400 AT). In 24 patients single photon emission $\mathrm{T}$ computed tomography was performed with the same gamma camera linked to a DEC PDP11/23 + com $\dot{\sim}$ puter that used locally written software. Ten ${ }_{0}^{\omega}$ minutes before the single photon emission? computed tomography study, $40 \mathrm{MBq}$ of $^{-}$ technetium-99 m $\left.{ }^{99 \mathrm{~m}} \mathrm{Tc}\right)$ human serum albumin was administered to allow blood pool imaging. A sequence of 64 simultaneous images of ${ }^{99 \mathrm{~m}} \mathrm{Tc}$ and ${ }^{111}$ In was then acquired as the head of the gamma camera rotated through $180^{\circ}$, starting in the righe anterior oblique position. The total imaging time was 32 minutes. At the end of this periodo computerised reconstruction of the images was performed.

\section{IMAGE INTERPRETATION}

An observer who was unaware of electrocardiographic findings or the maximum creatine kinase rise graded planar and single photon emission computed tomography images as positive (in which. indium activity was clearly seen in the region of the heart) or negative (where there was no detectable

Table 1 Patient details and results of imaging with indium-111 labelled autologous neutrophils

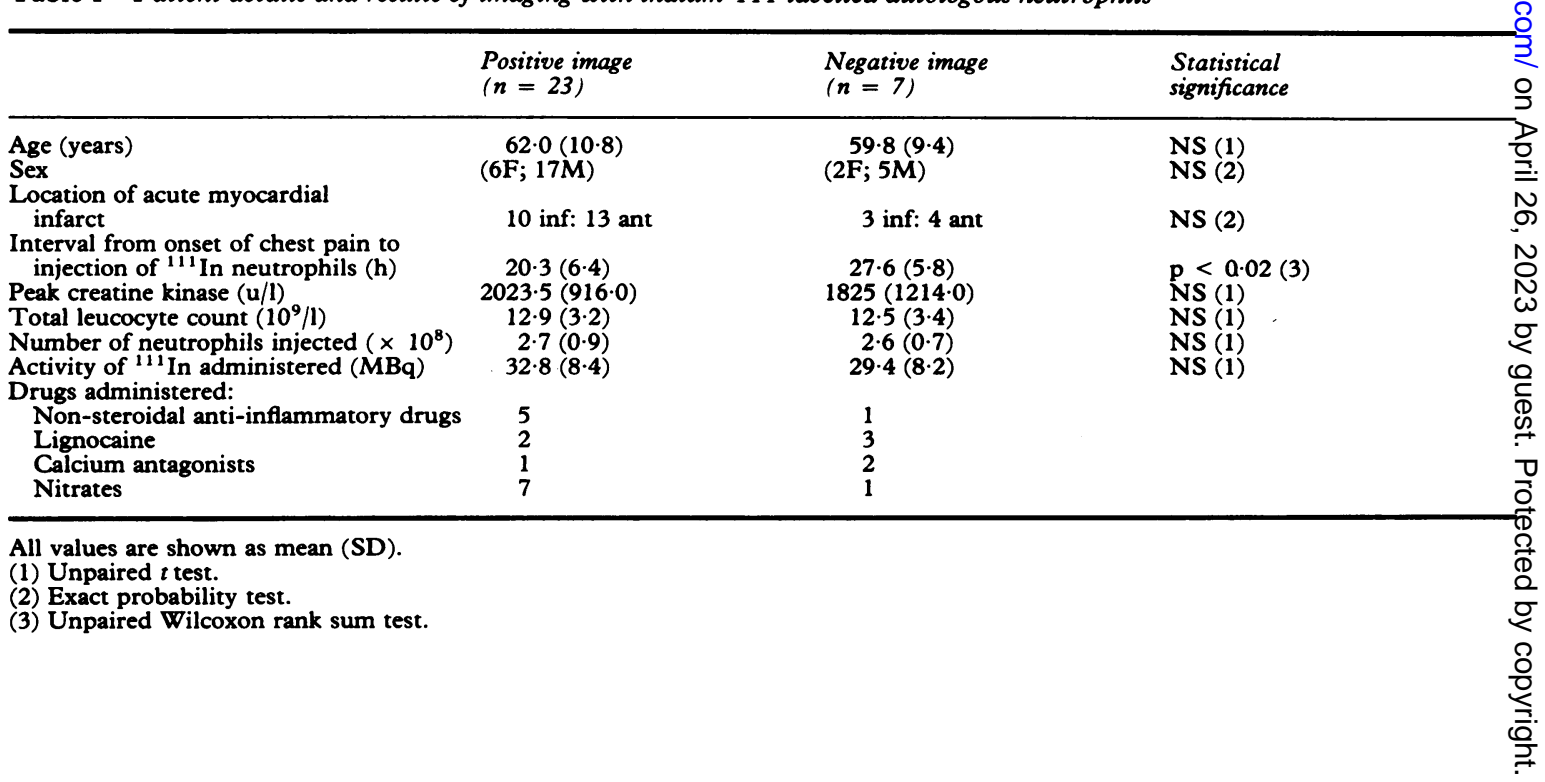


activity or where there was an area of activity on planar imaging that was inseparable from the liver, spleen, or ribs). Dual isotope single photon emission computed tomography images were considered to be positive when indium activity was seen in all three reconstruction views and corresponded with the ${ }^{99} \mathrm{~m}$ Tc blood pool image.

\section{STATISTICAL ANALYSIS}

Data from the groups were compared by means of an unpaired $t$ test, exact probability test, or unpaired Wilcoxon rank sum test as appropriate. Values of $p>0.05$ were regarded as not significant.

\section{Results}

In 23 of the 30 patients with acute myocardial infarction there was uptake of ${ }^{111} \mathrm{In}$ labelled neutrophils within the myocardium. Three patterns of cardiac uptake were seen ${ }^{5}$ : focal myocardial uptake (12 patients), diffuse myocardial uptake (3 patients), and "doughnut pattern" (3 patients). Figure 1 shows an example of myocardial uptake. Planar images from all patients were graded as unequivocally positive or negative. In six patients in whom the planar images were considered to be negative, single photon emission computed tomography reconstruction showed localised uptake within the myocardium (fig 2). In addition, dual isotope single photon emission computed tomography reconstruction improved anatomical localisation of the infarct by confirming uptake corresponding to the cardiac blood pool (fig 3 ). There is a significant difference between the intervals from onset of chest pain to injection of labelled neutrophils in the groups with positive and negative images $(p<0.02)$ (table 1). Furthermore, all patients reinjected within 18 hours had positive images whereas positive images were increasingly less common in those injected at progressively later intervals. Other features such as age, sex, peak creatine kinase, peripheral white blood cell count, dose of ${ }^{111}$ In administered, and drug treatment did not influence the imaging results (table 1 ).

\section{Discussion}

This study confirms that ${ }^{111}$ In labelled autologous neutrophils can be used to image the inflammatory response to acute myocardial infarction in man. The increased frequency of positive images in this study (77\% compared with the $58 \%$ as previously described $^{8}$ ) is in part related to earlier reinjection of ${ }^{111}$ In labelled neutrophils after the onset of chest pain. This suggests that the stimulus for activation and migration of neutrophils to the area of myo- cardial damage is transient. This temporal relation may be of particular relevance because of the current interest in reducing the extent of myocardial damage after myocardial ischaemia or infarction by the use of intravenous thrombolytic treatment ${ }^{1011}$ or the potential for the administration of lipoxygenase or cycloxygenase inhibitors. ${ }^{3}$

Thrombolytic treatment can produce coronary reperfusion and hence it could improve myocardial salvage, but it may result in other events which in themselves are potentially harmful. ${ }^{12}$ In particular, if the inflammatory response is exaggerated as a

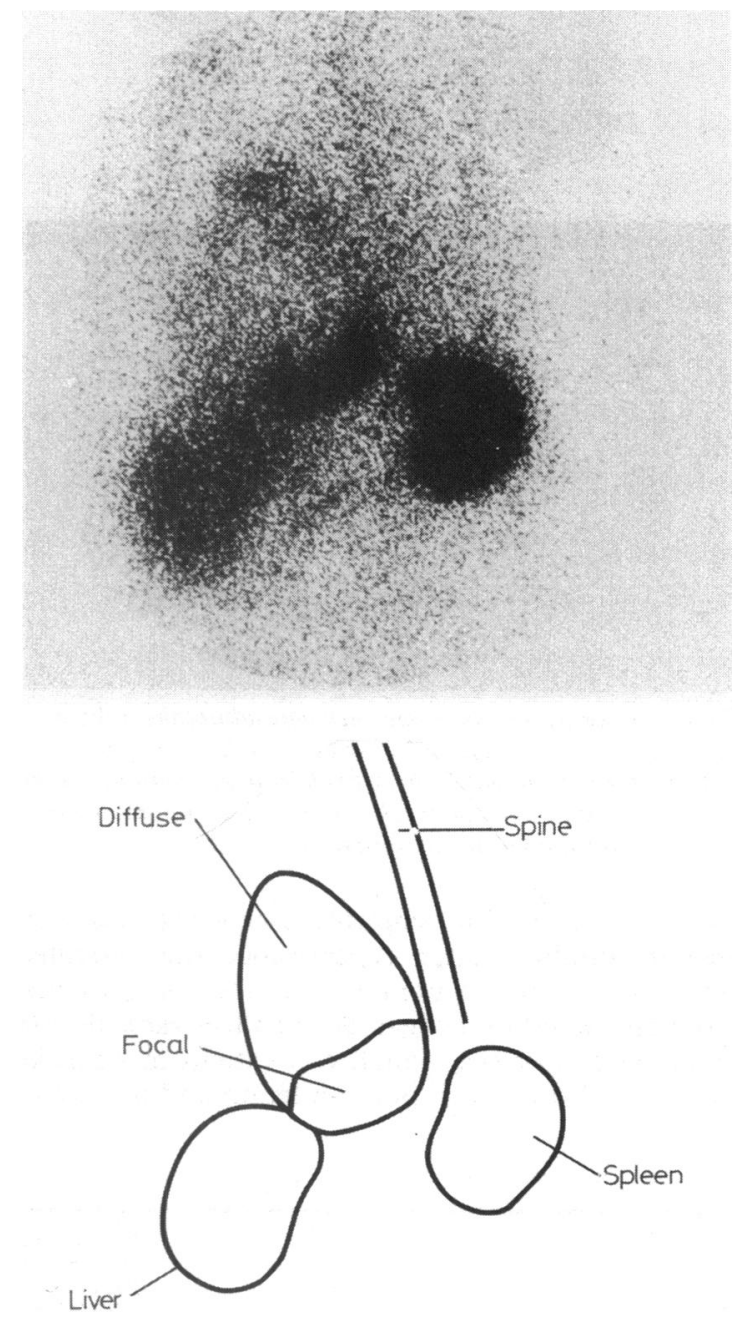

Fig 1 Planar image in the left anterior oblique view showing normal uptake of ${ }^{111}$ In labelled neutrophils in the liver and spleen and diffuse uptake in the region of the heart with an area of focal uptake in the inferior wall of the left ventricle. The line drawing shows the areas of uptake. 

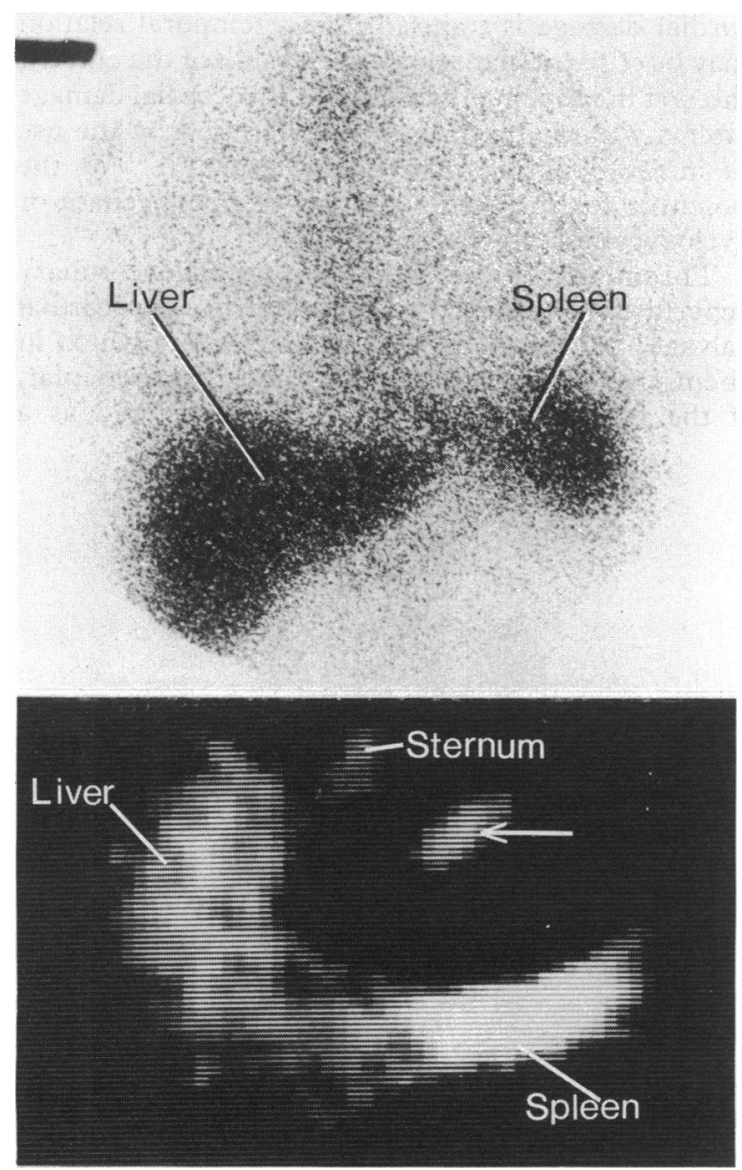

Fig 2 Anterior planar image with normal uptake in liver and spleen and no definite myocardial uptake (top). Single photon emission computed tomographic image (bottom) in the transverse plane showing uptake within liver and spleen and an area of focal myocardial uptake (arrowed).

result of neutrophils entering ischaemic tissue in greater numbers after reperfusion, the activated neutrophils could generate a number of cytotoxic products including oxygen derived free radicals and proteolytic enzymes, which can extend myocardial damage. ${ }^{13}$ Both neutrophil depletion and the use of

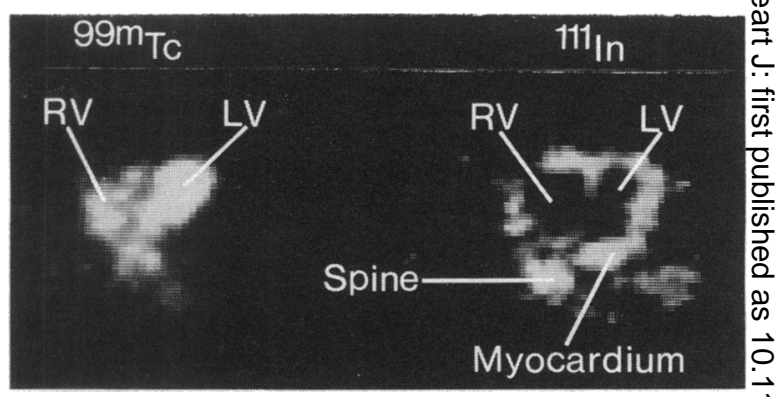

Fig 3 Simultaneous single photon emission computed tomographic images in the transverse plane. The ${ }^{99 \mathrm{~m}} \mathrm{Tc}$ image shows blood pool in the left and right ventricle. The corresponding ${ }^{111}$ In image shows extensive uptake within the myocardium of both ventricles.

non-steroidal anti-inflammatory drugs have been shown to reduce infarct size in experimental myo- cardial infarction, ${ }^{34}$ and these findings may indicate $c_{\Phi}$ further potential methods of improving myocardial salvage in the post-infarct period.

Single photon emission computed tomography increased the number of positive images by allowing $\infty$ spatial separation of positive myocardial uptake of.$v$ indium from adjacent bone, liver, and spleen. It is not possible to ascertain from the planar images whether the ${ }^{111}$ In activity detected in the region of the heart is due to blood pool activity. Dual isotope $\stackrel{2}{\varnothing}$ single photon emission computed tomography with $\stackrel{\mathbb{Q}}{\varrho}$ ${ }^{99 \mathrm{~m}} \mathrm{Tc}$ human serum albumin as a marker of blood $\overrightarrow{\overrightarrow{\hat{O}}}$ pool, however, unequivocally demonstrated that the 3 ${ }^{111}$ In activity was localised in the myocardium. Single photon emission computed tomography, like? pyrophosphate scans, ${ }^{14}$ may also provide a method of quantifying neutrophil uptake within the myocardium.

Imaging with ${ }^{111}$ In labelled autologous neutro- 3 phils in patients with acute myocardial infarction allows us to image the acute inflammatory response $\frac{}{3}$ to myocardial damage, but should not be regarded as $\mathrm{O}$ a technique for the diagnosis or localisation of acute myocardial infarction because other techniques are $\frac{D}{0}$ currently more successful. If inhibition of neutrophil migration limits the extent of myocardial $/$

Table 2 Imaging results

\begin{tabular}{|c|c|c|c|c|}
\hline \multirow[b]{2}{*}{ Time (h) } & \multirow[b]{2}{*}{$\begin{array}{l}\text { Number of } \\
\text { patients }\end{array}$} & \multicolumn{2}{|l|}{ Positive images } & \multirow[b]{2}{*}{ Positive images $\%$} \\
\hline & & $\begin{array}{l}\text { Planar positive } \\
\text { SPECT positive }\end{array}$ & $\begin{array}{l}\text { Planar negative } \\
\text { SPECT positive }\end{array}$ & \\
\hline $\begin{array}{l}18 \\
18-24 \\
24-36\end{array}$ & $\begin{array}{r}9 \\
12 \\
9\end{array}$ & $\begin{array}{l}7 \\
7 \\
3\end{array}$ & $\begin{array}{l}2 \\
3 \\
1\end{array}$ & $\begin{array}{r}100 \\
83 \\
44\end{array}$ \\
\hline
\end{tabular}

SPECT, single photon emission computed tomography. 
infarction this method can be used to monitor the temporal relation and extent of neutrophil uptake in acute infarction.

\section{References}

1 Mallory GK, White PD, Salcedo-Salgar J. The speed of healing of myocardial infarction. Am Heart $\mathcal{F}$ 1939;18:647-71.

2 Sommers HM, Jennings RB. Experimental acute myocardial infarction. Lab Invest 1964;12:1491-503.

3 Romson JL, Hook BG, Rigot VH, Schork MA, Swanson MS, Lucchesi BR. The effect of ibuprofen on accumulation of indium-111-labelled platelets and leukocytes in experimental myocardial infarction. Circulation 1982;66:1002-11.

4 Romson JL, Hook BG, Kunkel SL, Abrams GD, Schork MA, Lucchesi BR. Reduction of the extent of ischemic myocardial injury by neutrophil depletion in the dog. Circulation 1983;67:1016-23.

5 Weiss ES, Ahmed AD, Thakur ML; Welch MJ, Coleman RE, Sobel BE. Imaging of the inflammatory response in ischemic canine myocardium with ${ }^{111}$ indium-labelled leukocytes. $A m \mathcal{F}$ Cardiol 1977;40:195-9.

6 Thakur ML, Gottschalk A, Zaret BL. Imaging experimental myocardial infarction with indium-111labelled autologous leukocytes: effect of infarct age and residual regional myocardial blood flow. Circulation 1979;60:297-305.
7 McDougall IR, Baumert JE, Lantieri RL. Evaluation of ${ }^{111}$ In leukocyte whole body scanning. $A m \mathcal{F}$ Roentgenol 1979;133:849-54.

8 Davies RA, Thakur ML, Berger HJ, Wackers FJT, Gottschalk A, Zaret BL. Imaging the inflammatory response to acute myocardial infarction in man using indium-111-labelled autologous leukocytes. Circulation 1981;63:826-32.

9 Bell D, Millar AM, McGillivray M, Muir AL. The preparation and in-vivo behaviour of ${ }^{111} \mathrm{In}$-oxine labelled neutrophils separated from whole blood using mono-poly resolving medium. Nucl Med Commun 1986;7:447-53.

10 Mathey DG, Kuck KH, Tilsner V, Krebber HJ, Bleifeld $W$. Nonsurgical coronary artery recanalization in acute transmural myocardial infarction. Circulation 1981;63:489-97.

11 Been M, de Bono DP, Muir AL, Boulton FE, Hillis WS, Hornung R. Coronary thrombolysis with intravenous anisoylated plaminogen-streptokinase complex BRL 26921. Br Heart $\mathcal{F}$ 1985;53:253-9.

12 Braunwald E, Kloner RA. Myocardial reperfusion: a double-edged sword? $\mathcal{f}$ Clin Invest 1985;76:1713-9.

13 Werns SW, Shea MJ, Lucchesi BR. Free radicals and myocardial injury: pharmacologic implications. Circulation 1986;74:1-5.

14 Jansen DE, Corbett JR, Wolfe CL, et al. Quantification of myocardial infarction: a comparison of single photon-emission computed tomography with pyrophosphate to serial plasma MB-creatinine kinase measurements. Circulation 1985;72:327-33. 